\title{
Penanganan Cedera Olahraga Dengan Metode Rice
}

\author{
Meiky Fredianto ${ }^{1}$, Hafni Zuchra Noor ${ }^{2}$ \\ Departemen Bedah, Program Studi Pendidikan Dokter, Fakultas Kedokteran dan Ilmu Kesehatan, Universitas Muhammadiyah Yogyakarta \\ Email: meiky.fredianto@umy.ac.id \\ DOI: $10.18196 / \mathrm{ppm} .36 .316$
}

\begin{abstract}
Abstrak
Olahraga merupakan suatu gaya yang bekerja pada tubuh atau sebagian dari tubuh yang melampui kemampuan tubuh untuk mengatasinya. Dari kegiatan olahraga tersebut bisa terjadi cedera, baik karena jatuh, benturan ataupun salah gerak. Cedera olahraga (sport injury) adalah segala macam cedera yang timbul, baik pada waktu latihan maupun pada waktu berolahraga (pertandingan) ataupun sesudah pertandingan. Cedera olahraga biasanya terkena pada bagian tulang, otot, tendo serta ligamentum. Metode RICE merupakan suatu metode penanganan cedera, yang bertujuan untuk mencegah cedera lebih lanjut dan mengurangi rasa nyeri. Tujuan pengabdian kepada masyarakat ini adalah untuk memberikan bekal keilmuan dalam bidang penanganan cedera olahraga dengan metode RICE pada Rukun Krida Muda (RKM) di Desa Guyangan, secara teoretis dan praktis dalam meningkatkan pengetahuan penanganan cedera olaharaga di lapangan. Kegiatan ini dilaksanakan pada hari Minggu 27 September 2020 di desa Guyangan, Nogotirto. Metode yang digunakan dengan sosialisasi dan pelatihan yang disampaikan kepada Rukun Krida Muda (RKM) secara langsung namun tetap menerapkan protokol kesehatan secara tertib. Materi yang disampaikan pada sosialisasi ini adalah tentang penanganan cedera olahraga melalui dengan metode rice dan dilanjutkan pelatihan penanganan, didahului dengan sosialisasi sebelum diadakan pelatihan dan pengisian kuesioner di akhir kegiatan setelah mendapatkan perlakuan berupa sosialisasi. Kegiatan ini diikuti oleh 20 orang.

Hasil Kegiatan pelaksanaan program pengabdian masyarakat ini adalah sebagai berikut: 1) kegiatan sosialisasi penanganan cedera olahrga dengan metode RICE terlaksana dengan baik yang ditunjukan dengan tingkat keaktifan bertanya peserta dan 2) kegiatan pelatihan terlaksana dengan baik, setelah diberikan kuesioner sebanyak 14 responden (70\%) menunjukan kenaikan pemahaman penanganan cedera dan sebanyak 6 responden (30\%) masih belum menunjukan kenaikan pemahaman yang signifikan. Dapat disimpulkan ada perbedaan pengetahuan tentang penanganaan cedera olahraga dengan metode RICE setelah melakukan pelatihan.
\end{abstract}

Kata Kunci : Penanganan Cedera Olahraga, Metode RICE

\section{Pendahuluan}

Gaya hidup aktif secara fisik penting untuk semua kelompok usia. ${ }^{4-6}$ Alasan untuk berpartisipasi olahraga dan aktivitas fisik banyak, seperti itu sebagai kesenangan dan relaksasi, kompetisi, sosialisasi, pemeliharaan, dan peningkatan kebugaran. dan kesehatan. Aktivitas fisik yang teratur mengurangi risiko kematian dini secara umum, dan dari penyakit jantung koroner, hipertensi, kanker usus besar, obesitas, dan diabetes mellitus pada khususnya. ${ }^{4-6}$ Namun, partisipasi olahraga juga mengandung risiko untuk cedera, yang dalam beberapa kasus dapat menyebabkan kecacatan permanen. Studi Skandinavia mendokumentasikan bahwa cedera olahraga merupakan 10-19\% dari semua cedera akut terlihat di ruang gawat darurat. ${ }^{7-9}$ Efek dari cedera akibat berolahraga, dapat menimbulkan trauma bila cedera yang dialaminya akan mengganggu rutinitas dan aktivitas sehari-hari.

Bagi seorang olahragawan atau pelaku olahraga, cedera yang terjadi dapat menghambat dan atau menghentikan langkahnya untuk beraktivitas dan meraih prestasi yang lebih tinggi. Cedera yang terjadi harus mendapatkan pertolongan dan pengobatan sedini mungkin, agar para olahragawan atau pelaku olahraga tidak mengalami kesakitan yang lebih fatal dan dapat menimbulkan kecacatan, sehingga ia segera dapat mengikuti aktifitas fisik, berlatih dan bertanding kembali.

Dalam melakukan penangan cedera olahraga terlebih dahulu mengetahui bagian badan yang terkena cedera dan beratnya cedera tersebut. Secara umum, pasien tidak diperkenankan melakukan kegiatan olahraga seperti biasa sampai kelainan tersebut betul-betul membaik, dan dapat menggerakkan tubuh dengan nyeri yang minimal. Perlu sekali diingat bahwa bagian besar 
penyebab cedera tulang adalah akibat melakukan aktivitas sebelum waktunya. Olahraga adalah merupakan kegiatan yang rutin dilakukan untuk menjaga kebugaran tubuh, baik berupa jalan kaki, lari, senam dan berbagai bentuk olahraga yang lain. Dari kegiatan olahraga tersebut bisa terjadi cedera, baik karena jatuh, benturan ataupun salah gerak. Cedera tersebut bisa terjadi berupa strain maupun sprain. Sprain adalah robekan atau peregangan dari suatu otot, ligamen dan sendi, sedang strain adalah suatu kondisi nyeri pada otot yang disebabkan karena adanya tarikan yang berlebihan dari otot tersebut ${ }^{3}$.

Cedera ditandai dengan adanya rasa sakit, pembengkakan, kram, memar, kekakuan dan adanya pembatasan gerak sendi serta berkurangnya kekuatan pada daerah yang mengalami cedera tersebut. Sebelum ke rumah sakit, pertolongan pertama yang dapat dilakukan adalah evaluasi awal tentang keadaan umum penderita, untuk menentukan apakah ada keadaan yang mengancam kelangsungan hidupnya ${ }^{2}$.

Fenomena yang terjadi di Desa Guyangan, Nogotirto berdasarkan observasi mengenai pengetahuan tentang penangan cedera olahraga dengan metode RICE masih sangat rendah. Banyak para olahragawan yang dibiarkan saja ketika mereka mengalami cedera. Para pelaku olahraga masih mengandalkan massage tradisional. Selain itu, pengetahuan tentang metode RICE masih sangat kurang.

Metode RICE merupakan suatu metode penanganan cedera dengan menggunakan ice, yang bertujuan untuk mencegah cedera lebih lanjut dan mengurangi rasa nyeri. Dimana $\mathrm{R}=\mathrm{rest}$ (istirahat), $\mathrm{I}=\mathrm{ice}$ (es), $\mathrm{C}=\mathrm{Compresion}$ (kompres), $\mathrm{E}=$ elevation (elevasi) RICE adalah metode yang diterima secara umum untuk mengobati peradangan setelah trauma, seperti keseleo pergelangan kaki akut. Peradangan menyebabkan nyeri, edema, hiperalgesia, dan eritema, yang semuanya dapat membatasi kemampuan pasien untuk melakukan rehabilitasi yang diperlukan untuk penyembuhan yang tepat ${ }^{1}$. Melihat situasi seperti ini, tim pelaksana pengabdian kepada masyarakat mempunyai ide, gagasan dan inisiatif untuk melakukan pelatihan kepada remaja di Desa Guyangan, yang dimaksudkan dapat menjawab mengenai edukasi dan pengenalan gerakan serta cara menangani cedera olahraga melalui metode RICE. Diharapkan ide pengabdian ini dapat memberikan bukti pengembangan yang efektif.

\section{Metode Pelaksanaan}

Pengabdian ini dilaksanakan dalam beberapa tahapan yang mengacu pada produk/target luaran yang diinginkan. Adapun metode yang digunakan adalah dengan Penyuluhan/sosialisasi yang disampaikan oleh pemateri dr. Meiky Fredianto, Sp.OT (K) dan moderator dr. Hafni Zuchra Nor, MMR., Sp.BA dan dilanjutkan dengan pelatihan penanganan cedera oalahraga bagi mitra (Rukun Krida Muda Desa Guyangan).

Teknik pengumpulan data yang digunakan adalah melalui wawancara mendalam kepada remaja/warga, permasalahan yang dihadapi, solusi yang diperlukan, hasil yang didapat dari pelaksanaan pengabdian serta saran-saran bagi pelaksanaan pengabdian selanjutnya. Analisis data hasil pengabdian adalah dengan teknik deskriptif. Diuraikan secara narasi perencanaan, pelaksanaan dan hasil dari pengabdian serta permasalahan yang dihadapi selama pelaksanaan kegiatan dan solusinya. 


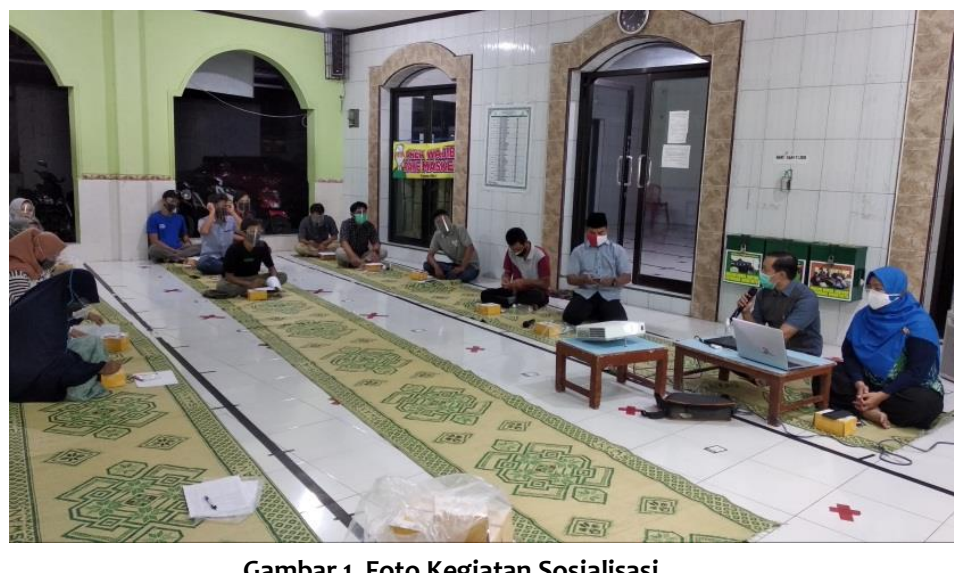

PKM ini melibatkan 20 Rukun Krida Muda (RKM). Metode yang digunakan dalam pelaksanaan kegiatan ini mencakup:

1. Melakukan sosialisasi tentang Penanganan Cedera Pada Saat Olahrga Dengan Menggunakan Metode RICE.

2. Melakukan Pelatihan, kesempatan ini diberikan untuk mempraktikan informasi dan pengetahuan mereka yang berkaitan dengan penanganan cedera olahraga yang telah mereka peroleh dari sosialisasi sebelumnya.

3. Setelah pelatihan dilaksanakan dilanjutkan dengan pengisian kuesioner untuk megetahui sejauh mana pemahaman pentingnya pengetahuan Penanganan Cedera Pada Saat Olahrga dengan Menggunakan Metode RICE.

\section{Hasil dan Pembahasan}

\section{Profil Responden}

Profil responden dalam penelitian ini meliputi usia, pekerjaan dan pendidikan. Adapun hasilnya adalah sebagai berikut:

\begin{tabular}{|c|c|c|c|}
\hline No. & Profil & Frekuensi & $\%$ \\
\hline \multirow[t]{5}{*}{1.} & Umur & & \\
\hline & $10-15$ tahun & 4 & 20,0 \\
\hline & $16-20$ tahun & 11 & 55,0 \\
\hline & $21-25$ tahun & 5 & 25,0 \\
\hline & Jumlah & 20 & 100,0 \\
\hline \multirow[t]{5}{*}{2.} & Pekerjaan & & \\
\hline & Pelajar & 7 & 35,0 \\
\hline & Mahasiswa & 10 & 50,0 \\
\hline & Pegawai Swasta & 3 & 15,0 \\
\hline & Jumlah & 20 & 100,0 \\
\hline \multirow[t]{4}{*}{3.} & Pendidikan & & \\
\hline & SMA & 7 & 35,0 \\
\hline & $\mathrm{S} 1$ & 13 & 65,0 \\
\hline & Jumlah & 20 & 100,0 \\
\hline
\end{tabular}

Tabel 1 menunjukkan bahwa sebagian besar responden berumur $16-20$ tahun, yaitu 11 responden $(55,0 \%)$, dan paling sedikit berumur $10-15$ tahun, yaitu 4 responden $(20,0 \%)$. Berdasarkan pekerjaan, sebagian besar adalah mahasiswa, yaitu 10 responden $(50,0 \%)$, dan 
paling sedikit adalah pegawai swasta, yaitu 3 responden (15,0\%). Berdasarkan pendidikan, sebagian besar responden berpendidikan S1, yaitu 13 responden $(65,0 \%)$, dan paling sedikit berpendidikan SMA, yaitu 7 responden $(35,0 \%)$.

Setelah diberikan kuesioner yang berisi mengenai pemahaman penanganan cedera pada saat olahraga dengan menggunakan metode RICE dihasilkan sebagai berikut :

Tabel 2. Deskripsi Pengetahuan tentang Penanganan Cedera Olahraga dengan Metode RICE Setelah Sosialisasi dan Pelatihan

\begin{tabular}{llll}
\hline Skor & Kategori & Frekuensi & $\%$ \\
\hline$>33$ & Sangat Tinggi & 0 & 0 \\
$22-32$ & Tinggi & 14 & 70 \\
$11-21$ & Rata-rata & 6 & 30 \\
$<10$ & Kurang & 0 & 0 \\
\cline { 2 - 4 } & Jumlah & 20 & 100,0 \\
\hline
\end{tabular}

Tabel 2 menunjukan bahwa setelah diberikan kuesioner, sebagian besar responden mempunyai pengetahuan tentang penanganan cedera pada saat olahrga dengan menggunakan metode RICE kategori tinggi, yaitu 14 responden (70\%), dan paling sedikit kategori rata-rata, yaitu 6 responden $(30 \%)$.

\section{Hasil}

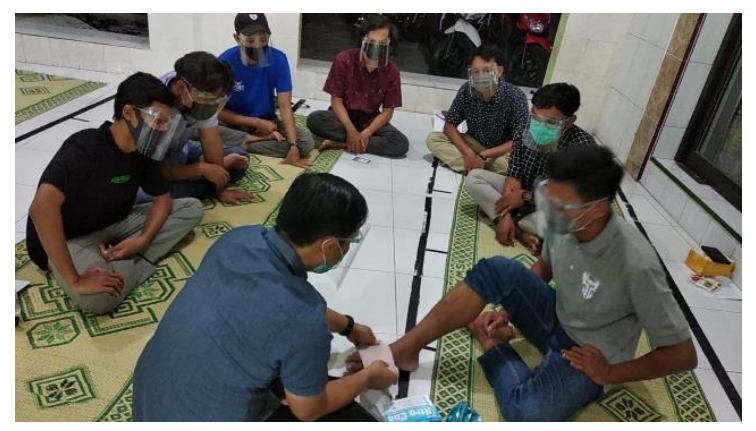

Gambar 2. Kegiatan Pelatihan

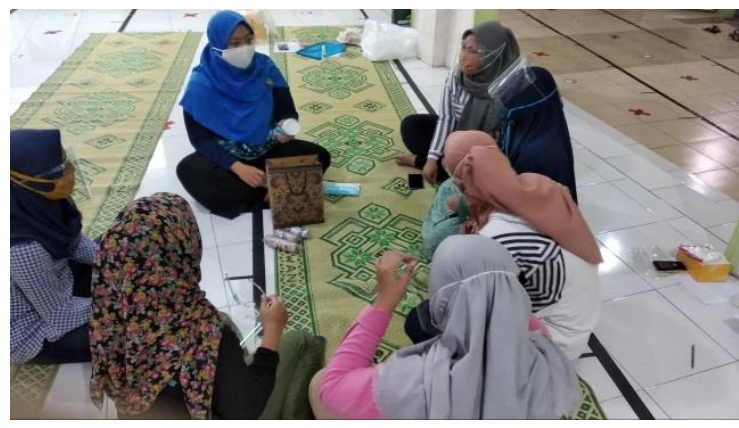

Gambar 3. Kegiatan Pelatihan

Berdasarkan analisis situasi yang dihasilkan dari kegiatan survei awal di Desa Guyangan, Nogotirto yang menyebutkan bahwa Rukun Krida Muda (RKM) masih merasa kesulitan dalam penanganan cedera olahraga dengan metode RICE. Berdasarkan hasil diskusi, para RKM menginginkan adanya pelatihan untuk pemahan yang lebih mendasar dan mudah dilaksanakan. Hasil diskusi disepakati diadakan sosialisasi dan pelatihan.

Kegiatan pengabdian yang bertujuan untuk membantu para RKM di Desa Guyangan, yaitu untuk memberikan bekal keilmuan dalam bidang penanganan cedera olahraga dengan metode RICE. Kegiatan pengabdian ini telah dilaksanakan pada hari Minggu 27 September 2020, bertempat di desa Guyanagan, Nogotirto dan diikuti oleh 20 peserta Rukun Krida Muda (RKM). Metode yang digunakan dengan sosialisasi yang disampaikan secara langsung namun tetap menerapkan protokol kesehatan secara tertib. Peserta dan tim menggunakan masker dan face shield yang sudah disediakan oleh tim pelaksana.

Terdapat dua metode yang digunakan dalam pelaksanakan pengabdian tersebut, yaitu sosialisasi dan pelatihan. Pada kegiatan pertama, yaitu sosialisasi, para peserta mendapatkan ilmu mengenai pemahaman tentang cedera olahraga, apa saja yang menjadi faktor risiko cedera olahraga, apa saja bentuk-bentuk dari cedera olahraga, serta bagaimana cara penanganan yang tepat jika terjadinya cerdera olahraga. Pada pelaksanaan sosialiasi, nampak sekali bahwa para 
peserta sangat antusias dalam mengikuti kegiatan ini. Para peserta sangat aktif mengajukan berbagai pertanyaan yang berkaitan dengan penanganan cedera olahraga dan mengutarakan permasalahan-permasalahan yang mereka hadapi saat berolahraga. Terjadi dialog dua arah yang aktif dalam kegiatan ini. Para peserta sangat antusias dalam mengikuti sosialisasi ini karena menganggap bahwa sosialisasi ini sangat penting dalam berolahraga dan bisa diterapkan ketika mengalami cedera.

Rangkaian kegiatan pengabdian tidak hanya meliputi sosialisasi saja. Kegiatan selanjutnya yang dilakukan sebagai rangkaian dalam kegiatan pengabdian ini adalah pelatihan. Pada kegiatan pelatihan, peserta diberikan kesempatan untuk mempraktikan informasi dan pengetahuan mereka yang berkaitan dengan penanganan cedera olahraga yang telah mereka peroleh dari sosialisasi sebelumnya. Masing-masing peserta pelatihan membuat kelompok yang terdiri 5 orang perkelompok dengan menerapkan physical distancing agar tidak berkerumun. Para peserta mempraktikan penanganan cedera menggunkan metode RICE dengan bahan yang sudah disiapkan oleh tim pengabdian. Diberikan tugas ini diharapkan para peserta pelatihan dapat mempergunakan pengetahuan mereka secara langsung atas bimbingan yang dilakukan para pemateri (pelaksana kegiatan pengabdian). Bimbingan ini sangat bermanfaat bagi para peserta pelatihan, karena pada saat mereka mempraktikan terlihat jelas mereka sudah paham akan penanganan jika terjadi cedera saat berolahraga. Serta pelatihan ini sangat berguna bagi para rukun krida muda yang mana mereka sedang senang-senangya menyalurkan hobi mereka yaitu olahraga, seperti bermain sepak bola, bersepeda, voly, bulu tangkis dll.

Pada akhir pelaksanaan pengabdian, diharapkan Rukun Krida Muda (RKM) mampu menangani secara mandiri dan tepat ketika mengalami cedera saat berolahraga. Selain itu para Rukun Krida Muda dapat berbagi informasi kepada masyarakat luas untuk menerapkan penanganaan secara tepat dan benar, sehingga tidak ada kejadian yang fatal akibat cedera olahraga.

\section{Simpulan}

Berdasarkan kegiatan pengabdian yang telah dilaksanakan, simpulan yang dapat diambil adalah sebagai berikut.

1. Pengabdian berupa sosialisasi penanganan cedera olahraga dengan metode RICE bagi Rukun Krida Muda (RKM) di Desa Guyangan, Nogotirto telah terlaksana dengan baik.

2. Pengabdian berupa pelatihan penanganan cedera olahraga dengan metode RICE bagi Rukun Krida Muda (RKM) di Desa Guyangan, Nogotirto dinyatakan berhasil setelah diberikan kuesioner sebanyak 14 responden (70\%) menunjukan kenaikan pemahaman penanganan cedera dan sebanyak 6 responden (30\%) masih belum menunjukan kenaikan pemahaman yang signifikan. Sehingga disimpulkan ada perbedaan pengetahuan tentang penanganaan cedera olahraga dengan metode RICE setelah melakukan pelatihan.

\section{Ucapan Terima Kasih}

Ucapan terima kasih kami tujukan terutama kepada pemberi dana LP3M UMY. Ucapan terima kasih juga kami tujukan kepada segenap Rukun Krida Muda (RKM) Desa Guyangan yang telah mengikuti pengabdian, serta semua kerabat kerja yang turut membantu dalam terlaksananya program pengabdian ini.

\section{Daftar Pustaka}


Van den Bekerom, M. P. J., Struijs, P. A. A., Blankevoort, L., Welling, L., van Dijk, C. N., \& Kerkhoffs, G. M. M. J. (2012). What Is the Evidence for Rest, Ice, compression, and elevation therapyin the treatmentofankle sprains in adults. J Athl Train2012;47:435-43.

Bahr R, L Holme. 2003. Risk factors for sports injuries - a methodological approach. Br J Sports Med 2003;37:384-392

Hing W, Lopes J, Hume PA, Reid DA (2011): Comparison of multimodal physiotherapy and "R.I.C.E." self-treatment for early management of ankle sprains. New Zealand Journal of Physiotherapy 39(1) 13-19.

Pate RR, Pratt M, Blair SN, et al. Physical activity and public health. A recommendation from the Centers for Disease Control and Prevention and the American College of Sports Medicine. JAMA 1995;273:402-7.

Fletcher GF, Balady G, Blair SN, et al. Statement on exercise: benefits and recommendations for physical activity programs for all Americans. A statement for health professionals by the Committee on Exercise and Cardiac Rehabilitation of the Council on Clinical Cardiology, American Heart Association. Circulation 1996;94:857-62.

Surgeon General's report on physical activity and health. From the Centers for Disease Control and Prevention. JAMA 1996;276:522.

Lindqvist KS, Timpka T, Bjurulf P. Injuries during leisure physical activity in a Swedish municipality. Scand J Soc Med 1996;24:282-92.

Ytterstad B. The Harstad injury prevention study: the epidemiology of sports injuries. An 8 year study. Br J Sports Med 1996;30:64-8. 6 de Loes M. Medical treatment and costs of sportsrelated injuries in a total population. Int J Sports Med 1990;11:66-72.

Arendt E, Dick R. Knee injury patterns among men and women in collegiate basketball and soccer. NCAA data and review of literature. Am J Sports Med 1995;23:694-701. 